2. Current Concerns in the Chemotherapy of Leprosy (B) Combined Therapy 


\title{
Combined Therapy in Leprosy
}

\author{
J. C. GATTI \\ Chief of the Center of Leprology, Chair of Infectious Diseases, \\ Faculty of Medicine of Buenos Aires, Maipu 863,5- $-^{\circ}$ Piso $-D^{\text {to }} A$, \\ Buenos Aires, Argentina
}

\begin{abstract}
We are submitting here our trials with combined therapy in leprosy. The following combinations of drugs were used.

(a) Dapsone $25 \mathrm{mg}$ daily plus rifampicin $300 \mathrm{mg}$ daily in 43 out-patients, of whom 32 had lepromatous leprosy;

(b) Dapsone $50 \mathrm{mg}$ or $100 \mathrm{mg}$ daily plus rifampicin $300 \mathrm{mg}$ daily in 70 in-patients with lepromatous leprosy in the Sanatorio Colonia Baldomero Sommer.

(c) Dapsone $25 \mathrm{mg}$ daily plus clofazimine $200 \mathrm{mg}$ weekly in 38 outpatients with lepromatous leprosy.

(d) In addition, comment is made on 4 patients with lepromatous leprosy in whom the addition of dapsone to clofazimine resulted in an improvement in bacteriological status.
\end{abstract}

We believe that combined therapy is useful because it not only produces clinical and bacteriological improvement in patients with lepromatous leprosy, but also induces fewer and less severe reactional episodes. Furthermore, it has a lower tendency to favour the development of resistance.

\section{Introduction}

The introduction of an increasing number of drugs in the treatment of leprosy during the last three decades has been largely on theoretical grounds because of a lack of knowledge of the responsible organism, Myco. leprae, and of the pathogenesis of the disease. The effectiveness of single drugs like dapsone, the long acting sulphonamides, thiambutosine, thiacetazone, ethionamide, etc., is decreased by the reactional states they often appear to induce and by the emergence of resistant forms. Some of these drugs e.g. ethionamide demonstrate crossed resistance with other drugs.

We therefore need a form of combined therapy for use in the multibacillary forms of leprosy that can be compared with use in tuberculosis. In this disease it has been shown that after a preliminary period of treatment with 2 or 3 drugs the number of bacilli decreases dramatically, and therefore the incidence of resistance.

The present ideas about combined therapy began to gain currency in Rio de Janeiro in 1963, when the Therapeutic Committee of the VIII International Leprosy Congress advised its use; it was again asserted in London, 1968. The Therapeutic Committee of the Tenth International Leprosy Congress (Bergen, 1973) stated regarding combined therapy. "Concurrent administration of drugs like thiambutosine, long acting sulphonamides, thiosemicarbazone, clofazimine and rifampicin along with dapsone has been tried in the treatment of leprosy with 
a view to obtain a synergistic effect and also to prevent the development of sulphone resistance. The results of the trials are not uniform, some found the combined treatment better than dapsone alone, while others did not notice any substantial difference." Further, it says regarding resistance, "Clofazimine and rifampicin, either alone or in combination with dapsone (or other drugs such as thiambutosine or ethionamide) have been found to be effective in the management of cases". Its criteria are based on the observation that the real effectiveness of the first-line drugs (sulphone, long acting and repository sulphonamides, clofazimine and thiambutosine) is frequently reduced by the reactional states that often necessitate the reduction of the dose or the change of drug, or even the stopping of the specific medication.

We wanted to obtain a synergistic effect, and prevent the development of sulphone resistance, or resistance to the first line drug with which treatment began. We believe that in the use of combined therapy the therapeutic effect of each drug should be considered, the indications for it, and the counter-indications against it ("Leprosy Treatment Actualization", Second National Leprosy Meeting, Buenos Aires, November 1968).

Our experience with combined therapy began 9 years ago ("First trials on lepromatous patients treatment with associated medication"-J. C. Gatti, J. E. Cardama, M. H. Farina, L. M. Balina, F. F. Wilkinson, O. Bianchi and J. J. Avila. El Dia Medico Practico 20-VIII-65 P. 4, and Leprologia 1965-X (2) 179.). At first we combined dapsone with sulphamethoxypyridazine or sulphamethoxydiazine in the following ways:

(1) Ingestion of 1 pill daily; dapsone $25 \mathrm{mg}$, sulphamethoxydiazine $250 \mathrm{mg}$, excipient to $500 \mathrm{mg}$

(2) Ingestion of 1 pill daily; dapsone $25 \mathrm{mg}$, sulphamethoxypyridazine $250 \mathrm{mg}$, excipient to $500 \mathrm{mg}$.

After 6 months we concluded, "They are useful medications and of great future in the leprologic field and they justify going on with the first trials". Nine years after those first patients were treated we can state that the clinical, bacteriological and histological effects are, in more than 50 patients with all types of leprosy, similar to those found with sulphone, with a better tolerance to the drug and fewer reactional phenomena. Furthermore, we think this combined therapy is useful in patients with sulphone resistant bacilli.

\title{
Our present combined therapy. 1. Dapsone plus rifampicin
}

(a) Out-patient trials

\section{Dose}

Dapsone $25 \mathrm{mg}$ daily with rifampicin $300 \mathrm{mg}$ daily.

\section{Number of cases}

Total: 43 patients (all out-patients) classified thus:

\author{
32 lepromatous \\ 3 tuberculoid \\ 1 borderline \\ 4 indeterminate \\ 2 reactional tuberculoid \\ 1 reactional lepromatous (ENL).
}




\section{Period under observation}

Between 3 and 24 months.

\section{Tolerance}

Generally good. Eight patients developed ENL of variable intensity. We have always tried to administer thalidomide concurrently, trying not to stop the specific medication; in some cases we had to reduce it for a few days. One patient developed symptoms of ulnar neuritis (epitrochlear pain). One patient developed gastric and hepatic disturbance.

\section{Results}

Of 3 tuberculoid cases treated from 4 to 10 months, 2 showed complete resolution. The third patient showed improvement in skin lesions, but developed acute neuritis which was treated with clofazimine $100 \mathrm{mg} /$ day, since we consider this useful in neuritis.

Most of the patients with lepromatous leprosy showed obvious clinical improvement, mainly in the nodules, and seen after the first few months. Bacteriological improvement was similar to that with dapsone, but was most evident in early cases like the 4 with indeterminate leprosy, the borderline and the early lepromatous. Patients with advanced lepromatous leprosy and those already showing resistance to the initial therapy have shown less improvement in Morphological and Bacteriological Index. Nevertheless, 4 of these cases had negative smears after 12 months with this therapy.

\section{Histology}

In 5 patients with lepromatous leprosy treated for more than 1 year, the histopathology showed an obvious decrease of ,the lepromatous infiltration, with fewer Virchow cells and fewer bacilli, which were fragmented and granular.

Two patients with reactional tuberculoid leprosy improved clinically and bacteriologically after 2 months. The one patient with reactional lepromatous leprosy needed additional thalidomide in order to control the reaction.

\section{(b) In-patient trials}

The following trial has been made in Sanatorio Baldomero Sommer by Drs R. O. Manzi, I. Simonovich, J. Ganopol and R. L. Guaraz.

The in-patients chosen have lepromatous leprosy (L2, L3) and have received sulphone for 3 to 10 years in a dose from 50 to $100 \mathrm{mg} /$ day. Nevertheless these patients did not improve clinically and bacteriologically. It was therefore decided to use rifampicin $300 \mathrm{mg} / \mathrm{day}$ and dapsone $50-100 \mathrm{mg} / \mathrm{day}$, except in those patients with severe reactional states or kidney impairment who received $25 \mathrm{mg}$ dapsone. Rifampicin was used at a dose of $300 \mathrm{mg}$ daily because it is expensive and because of the visceral lesions some patients had. It was combined with dapsone to diminish the risk of resistance, but this is a low dose when compared with that customary in tuberculosis. These 70 patients included 24 with previous reactions who also received thalidomide. 


\section{Methods}

The most important lesions observed were, nasal obstruction, nodules, infiltration, reactions and loss of voice. Investigations included clinical control, photography, skin smears and histopathology. Patients were between 20 and 63 years old, and were treated for from 3 to 15 months.

Twenty-four patients presented reactional states during the trial; they were given thalidomide 100 to $300 \mathrm{mg} /$ day in addition to the combined therapy.

\section{Results}

Nasal obstruction This was the first symptom to disappear; this was evident in from 7 to 15 days.

Nodules New nodules did not develop during the treatment. Old nodules began to subside within 15 to 30 days and resolution was obvious after 3-4 months.

Infiltration The infiltration lessened within 15 days, and resolution was obvious after 4 months. One of the patients stopped the treatment. One month later he developed an infiltrated lesion on the buttocks the size of the palm of the hand, which disappeared when he resumed treatment. Twelve patients who had itching, epistaxis, joint pains, ulcers and loss of voice improved in a similar way.

Reactions In 6 out of the 24 patients, the reactional states were less violent and less frequent, so that thalidomide could be stopped. The other 18 patients had no obvious changes in their reactional state.

Smears After 2 months, 90\% had negative nasal smears, in 10\% the B.I. and M.I. improved. Skin smears improved less rapidly than the clinical lesions, but the M.I. decreased.

\section{Conclusions}

(1) Tolerance to this combined therapy was good.

(2) The results varied between good and excellent in all patients.

(3) Ninety per cent had negative nasal smears in 2 months.

(4) The B.I. presented no evident changes, but there were important falls in the M.I.

(5) After 15 months of treatment, resistance to this form of treatment had not developed.

(6) Trials should be continued to assess long term results.

\section{Our Present Combined Therapy 2. Dapsone with clofazimine}

Dose

Dapsone $25 \mathrm{mg} /$ day plus clofazimine $200 \mathrm{mg} /$ week.

\section{Number of cases and clinical types}

Thirty-eight patients with lepromatous leprosy, all out-patients, of whom 16 had had no previous treatment, and 22 had become resistant to the first therapy, having been treated for more than 5 years. 


\section{Period of observation}

Between 6 and 35 months.

\section{Tolerance}

Good. The typical pigmentation after clofazimine was not so evident as with the usual dose of the drug. Three patients developed ENL. They improved after receiving thalidomide in addition.

\section{Results}

No new lesions developed. In all cases after the first month of treatment, lesions began to lose their infiltration and the nodules began to get smaller. This was quite evident during the sixth month, when these lesions were definitely atrophic and the surface was wrinkled by folds. After the first month, bacteriological improvement was confirmed in regard to the number and morphology of bacilli. Bacilli decreased in number and they became granular.

\section{Histology}

After 6 months biopsies showed histological improvement. There was a decrease in the number of Virchow cells and the appearance of fibroblasts.

\section{Interesting points}

A report was made at the IX International Leprosy Congress (London, 1968) on 30 patients treated with clofazimine. Interesting points in the subsequent progress of 4 of these patients deserve mention.

Case No. 1 Lepromatous. He received clofazimine $300 \mathrm{mg} /$ day for 16 months. Smears became negative. Clofazimine was then reduced to $200 \mathrm{mg} /$ day for 11 months, and smears became positive again, but when we associated dapsone $25 \mathrm{mg} /$ day with clofazimine $200 \mathrm{mg} /$ week, smears became negative in 3 months.

Case No. 2 Lepromatous. He received clofazimine $100 \mathrm{mg} /$ day for 26 months without bacteriological improvement. After that we associated dapsone $25 \mathrm{mg} /$ day with clofazimine $200 \mathrm{mg} /$ week and smears became negative in 6 months.

Case No. 3 Lepromatous. He received clofazimine $100 \mathrm{mg} /$ day for 37 months with the following bacteriological result; the B.I. fell from 4 to 3 . The M.I. rose from 1 to 4 . After that we combined dapsone $25 \mathrm{mg} /$ day with clofazimine $200 \mathrm{mg} /$ week for 6 months, and smears became negative.

Case No. 4 Lepromatous. He received clofazimine $100 \mathrm{mg} /$ day for 28 months, at which point the B.I. had fallen from 5 to 2 but the M.I. had risen from 3 to 7 . After that dapsone $25 \mathrm{mg} /$ day was combined with clofazimine $200 \mathrm{mg} /$ week and smears became negative after 4 months.

\section{Conclusion}

We believe that combined therapy is useful because it not only leads to clinical and bacteriological improvement in patients with lepromatous leprosy, but also to reduction in reactional episodes both in number and intensity. Furthermore, there appears to be a diminished risk of the development of drug resistant forms of the bacillus, and also of overcoming the effects of true drug resistance of genetic origin. 


\section{Acknowledgement}

We gratefully acknowledge the help given by Dr Manzi and others of the Sanatorio Colonia Baldomero Sommer, and also the contribution from Drs J. E. Cardama and L. M. Balina and others of the Skin and Leprosy Service of the Muniz Hospital. 